\title{
The Induction of After-Death Communications Utilizing Eye-Movement Desensitization and Reprocessing: A New Discovery
}

\author{
Allan L. Botkin, Psy.D. \\ Libertyville, IL
}

\begin{abstract}
A number of authors have described after-death communications (ADCs), in which bereaved individuals experience what they believe is actual spiritual contact with the deceased. ADCs are consistently reported as profoundly loving experiences that greatly assist the grieving process. Although most researchers have argued that ADCs can occur only spontaneously, Raymond Moody's research has indicated that we do have some control over the production of the experience. In this paper I describe a new induction technique that produces ADCs in a more reliable, rapid, and efficient manner. ADCs induced by this new technique provide a more elaborated experience that often fosters complete resolution of grief. These induced ADCs also appear to be much more like near-death experiences (NDEs) than do spontaneous ADCs, which strongly suggests that NDEs and ADCs may be essentially the same phenomenon.
\end{abstract}

Since earning my Doctor of Psychology degree from Baylor University in 1983, I have worked in private practice and on a specialized inpatient psychiatric trauma unit. My area of specialty has been the diagnosis and treatment of posttraumatic stress disorder (PTSD) and grief. About two years ago, I began to use a relatively new and very powerful psychological treatment in a different way. My intent was simply to make an already very powerful method more efficient. However, something very strange began to happen. A good number of my patients reported to me that they had actually made spiritual contact with the deceased person they were grieving. Moreover, when patients had this

Allan L. Botkin, Psy.D., is a clinical psychologist and Program Coordinator of the Intensive Trauma Program at the Veterans Administration Medical Center, North Chicago, IL, and in private practice. Reprint requests should be addressed to Dr. Botkin at 1144 Harms, Libertyville, IL 60048. 
kind of experience, their grief suddenly and completely resolved. I immediately became curious about whatever it was that was producing these experiences. I retraced the steps taken in each case the experience occurred, as well as in each case the experience did not occur. I was able to identify the essential psychotherapeutic components that produced the experience. By combining these components and further refining the procedure, I discovered that I could induce the experience in nearly all of my patients.

This kind of experience is not rare for people who grieve, and they have been recorded throughout history. The phenomenon has been recently described by a few authors who have either conducted surveys, or worked directly with grieving patients. The experience is now commonly referred to as an "after-death communication," or ADC. However, the current thinking in the field is that ADCs are always spontaneous, and cannot be willfully or purposefully produced. In fact, one author speculated that we will never be able to induce ADCs (LaGrand, 1997). The current belief is that some people are just fortunate enough to have an ADC and experience its therapeutic benefits, while others, for some unknown reason, are not.

\section{Spontaneous ADCs}

At least four books have been recently published on ADCs. The first of these was Hello From Heaven! (1996), by Bill and Judy Guggenheim. They presented the results of an extensive survey of generally normal and healthy individuals who reported spontaneous spiritual encounters with deceased friends and loved ones. They labeled these experiences "after-death communications," or ADCs. The authors collected first hand accounts of ADCs from 2,000 people. They estimated that as many as 20 percent of the population in the United States have experienced ADCs. Since an estimated 4 percent of the population has experienced near-death experiences (NDEs), the occurrence of ADCs is about five times greater than that of NDEs. The percentage of ADCs for parents who have lost children to death and for widows is even higher.

The most remarkable aspect of this survey, for me, was that the 353 personal accounts of ADCs reported in the book were identical in many ways to the experiences my patients have been reporting to me, both in terms of the content of the experience and its overwhelmingly positive psychological consequences. I was immediately convinced that, in essence, we were dealing with the same phenomenon. One 
major difference, however, is that the Guggenheims made the argument that ADCs can only occur spontaneously, and that they cannot be purposefully produced. Other ADC researchers generally make the same claim.

The Guggenheims described 12 types of spontaneous ADCs: sentient $\mathrm{ADCs}$, one of the most common types, involve sensing or feeling the presence of the deceased; auditory ADCs, also common, involving hearing the voice of the deceased or receiving a verbal message; tactile ADCs, involving feeling a physical touch by the deceased; olfactory ADCs, involving smelling a fragrance that is associated with the deceased; visual ADCs involving seeing the deceased; ADC visions that include some form of two-way telepathic communication, distinguished from visual $\mathrm{ADCs}$ in that they involve "bright, vivid colors, that radiate their own inner light"; twilight ADCs, occurring just as people are falling asleep or waking up; sleep-state ADCs, occurring when a person is asleep, but experienced as very different from dreams; out-of-body ADCs, involving contact with the deceased while the survivor is in an out-of-body state, which may be comparable to NDEs and include going through a tunnel and towards a light before meeting the deceased; telephone $\mathrm{ADCs}$, the least common form of $\mathrm{ADC}$, in which people have reported actually receiving a phone call from the deceased when awake; ADCs of physical phenomena, involving unusual physical events perceived as a message from the deceased, such as a light being turned on or off, or a door being opened or closed; and symbolic $\mathrm{ADCs}$, involving something in the physical environment that survivors interpret as a sign from the deceased, such as butterflies or rainbows.

The experiential quality and content of the various sensory components of spontaneous and induced ADCs are essentially identical. People who have had either a spontaneous or an induced ADC describe the sensory components of their experience in the same way. All indications are that the two are the same phenomenon. There is, however, one major difference. Induced ADCs, as opposed to spontaneous ADCs, are almost always multisensory in nature, and typically involve at least the visual and auditory components, and frequently the radiant quality of the $\mathrm{ADC}$ vision as well. The tactile and the olfactory components are also sometimes reported in induced ADCs. The NDE-like qualities of some out-of-body ADCs are also included in many induced ADCs; however, none of my patients ever reported an out-of-body experience concurrent with his or her ADC. It appears that, in general, that the more multisensory and elaborated ADCs are, the more similar they are to NDEs. That is why induced ADCs are actually more similar to 
NDEs, than to spontaneous ADCs. This also appears to explain why spontaneous ADC researchers have apparently not considered ADCs and NDEs to be the same phenomenon.

The reason that induced ADCs are more multisensory and elaborated is that the induction procedure allows much greater control of the experience, both in terms of initiating the experience and developing the different aspects of it. The main reason this difference is important is that increased control and elaboration clearly enhances the therapeutic value of the experience, which is consistent with my reading of the available case material. To offer an analogy, in many cases, the spontaneous ADC is like recognizing an old friend by chance passing in a car going the opposite direction on a highway, whereas the induced ADC is like driving to your friend's house so you can sit down and talk for a while.

I am also not convinced that all 12 types of spontaneous ADCs listed above are true ADCs, which are clearly identifiable by their universal quality and content. It appears that some of the above categories of spontaneous $\mathrm{ADCs}$ are very different in this respect, and could possibly be explained by known psychological mechanisms. I am not arguing that some of these experiences are not of therapeutic value, but only that they may be a different phenomenon. "Sensing" the presence of the deceased, for example, may be very comforting, but it could simply be an activation of the memory of what it felt like to be with the deceased before death. Twilight ADCs may be simply hypnagogic or hypnopompic phenomena. ADCs of physical phenomena and symbolic ADCs, which also do not involve a direct sensory experience, may have more to do with the healing powers of imagination or intuition. With ADC inductions, these experiences would only be a starting point, in terms of creating a receptive mode, so that a direct and fully elaborated multisensory experience can occur, which will not just assist the survivor in the grieving process, but most likely provide complete resolution.

Since the Guggenheims published the results of their survey, three other books on spontaneous ADCs have been published by different authors. Edie Devers, a practicing psychotherapist, published Goodbye Again in 1997, based upon her research for her M.S.N. and Ph.D. degrees. As the other books described here on spontaneous ADCs, she provided actual case material that illustrated the loving content of ADCs and the personal convictions of experiencers in the spiritual reality of ADCs. Devers believes, as I do, that the therapeutic value of ADCs is due to establishing the feeling of reconnection with the deceased. 
With regard to the psychological state necessary to experience an ADC she wrote:

Most who have had ADC believe that certain states of consciousness are more conducive to it than others... Some people believe that being in a state of quiet is the only way to experience the deceased. Others said that because they were so exhausted physically and emotionally by grief, their defenses were down; thus they were in a receptive state to experience the deceased.... Others believe that one only needs to be receptive to the idea of $\mathrm{ADC}$ to be capable of experiencing it. (Devers, 1997, pp. 19-21)

Devers continued:

However, having a receptive mind-set alone does not guarantee an experience for everyone. Some people who want to have experiences do not have them, and others have them, unexpectedly. In most cases the experience is initiated by the deceased.... People who try to contact the deceased are generally unsuccessful. (1997, p. 22)

Devers reported that not all experiencers are immediately helped by an ADC, and that for some, ADCs leave people with a negative feeling because they either reexperience an old conflict with the deceased, or because they feel they lose the deceased all over again when the ADC ends. Devers also pointed out that "Though [ADC] communication is usually brief and simple, it can be complicated and ongoing. When it is extended, it often not only leads to grief resolution but also helps heal the relationship between the living and the deceased" $(1997$, p. 29). Thus, because of the brief nature of many spontaneous ADCs, sometimes not only is resolution not possible, they can at times intensify the unresolved negative feelings associated with the loss.

I believe that Devers correctly identified the receptive mode as the psychological state necessary to achieve an ADC. The only ingredient missing here is a method to increase or maximize the receptive mode. Of course, that is exactly what my induction technique provides. Also, because of the reliability and control in ADC inductions, all induced ADC experiences can be rather easily extended and elaborated, thereby allowing resolution of all grief and relationship issues.

Alexandra Kennedy published Your Loved One Lives On Within You in 1997. Kennedy focused on the problem of unfinished business for the bereaved that frequently accompanies unresolved grief. Although her goal was to help people establish a reconnection to deceased loved ones, she did so by helping survivors develop their powers of imagination. By strengthening imaginational skills and focusing on the deceased 
through such techniques as internal communication, letter writing, dialogue, and imagery, the bereaved are assisted in working through a variety of unresolved issues. Whether these experiences are actual contacts with the dead is less an issue for Kennedy than helping those who suffer. She purposefully did not attempt to make a distinction between purely psychological products of imagination and the more universal content of ADC experiences. Some of the experiences of her clients are suggestive of true ADCs, while others are clearly products of imagination. For example, she instructed her clients to carry on internal conversations not only with the deceased, which sometimes triggers an ADC, but also with living family members and friends. Although internal conversations in general appear to be psychotherapeutically helpful, they tend to be highly individualized and do not offer the sudden and dramatic psychotherapeutic shifts of true ADCs. ADCs that do occur in the course of Kennedy's treatment were therefore somewhat inadvertent, which makes it significantly different from the approach to ADC induction described below.

Another recently published book, After-Death Communication: Final Farewells (1997) was written by Louis LaGrand, a Distinguished Service Professor Emeritus at the State University of New York. His conclusions were based upon 15 years of experience with the bereaved, and generally support the findings of Guggenheim and Guggenheim. LaGrand, as many other professionals who have worked closely with grieving patients, appears to have come to believe in the spiritual authenticity of $\mathrm{ADCs}$, and made a strong argument for his case.

LaGrand began his analysis of ADCs by stating: "It is important to emphasize that the living person is not actively seeking to make contact with the deceased.... Instead it is the deceased... who seems to reach out" (1997, p. xiii). LaGrand later in his book offered some speculation as to why all mourners do not experience ADCs. He wrote:

What I am getting at is that it may well be impossible to obtain scientific evidence to say unequivocally that the contact experience is, beyond a shadow of a doubt, true. Unfortunately, but undeniably, the evasiveness of the contact experience is another reason mainstream scientists have shunned investigation of the phenomena. Who is ever going to pull off an apparition in a laboratory setting? Who will be able to obtain the cooperation of a deceased husband to talk to his widow with researchers standing by in white coats with pencils poised? ... I regret to say at this time that such a demand cannot be met, and probably never will be. (1997, p. 164)

It will be clear below that LaGrand's beliefs about the importance of who 
initiates the contact, and his related pessimism about the possibility of scientific study, are no longer warranted.

In summary, then, these authors, who have had considerable experience in working with or researching individuals who have had spontaneous ADCs, come to some similar conclusions. They uniformly recognize, for example, that spontaneous ADCs significantly assist survivors in the grieving process. Yet, the process or mechanism that produces the spontaneous ADC is viewed as either a matter of speculation, or as even beyond what is knowable. It should be clearly pointed out, however, that I am not the first to induce ADCs with any consistent success. Raymond Moody began experimentation with inducing ADCs some years ago and wrote a book on the topic a few years before these more recent books on spontaneous $\mathrm{ADCs}$ were published.

\section{Moody's Induced ADCs}

In 1992, Moody published a report in this Journal, followed by his book Reunions in 1993, in which he described the experiences that subjects in his study had with departed loved ones. He induced ADCs in his subjects by utilizing the method of mirror gazing, which was developed by the ancient Greeks. In his initial study, he gathered ten emotionally healthy, professional people. Moody spent nearly an entire day with each subject individually, generally talking about the departed loved one and assisting the subject in getting into a relaxed state. At dusk the subject would sit in front of a mirrors in a setting designed to promote the experience. Of the ten subjects, five experienced ADCs. Moody reported that he has been able to increase the odds of inducing ADCs since his original study, but he did not provide any additional numbers.

Moody therefore demonstrated that not all ADCs are purely spontaneous, and that we do have some control over their production. I strongly suspect, however, that the mirror gazing itself had less to do with the production of ADCs in his study, than did his rather involved and prolonged preparation for the experience, which assisted his subjects in achieving a relaxed and receptive state. It would not be surprising if a number of different induction procedures would work if a person were in the right frame of mind. After all, ADCs occur spontaneously under a variety of circumstances, when a person quite by chance happens to be in the appropriate receptive mode.

The main advantages of using the induction procedure described below are that it is faster, more efficient, and more under the control of 
both the therapist and the experiencer. It is faster because this technique has the power to induce rapidly the psychological state necessary to achieve the experience; it literally takes only a few minutes. Also, the success rate of the method provided here is $\mathbf{9 8}$ percent for first attempts, which points to the greater efficiency of this method. It offers greater control of the experience because if certain issues are left unaddressed and unresolved after an initial ADC, which happens rather frequently, it is a simple matter to induce the experience again and proceed until all issues are sufficiently resolved.

\section{The Discovery of the Induction Technique}

Perhaps the most startling aspect of the discovery presented here is that these experiences are actually rather easy to produce. It does not matter if the loss is traumatic, such as the death of a child or battlefield buddy, or if the death is the more usual variety, such as the death of a grandparent. It does not matter if the death was recent, or if it occurred many decades in the past. It also does not matter what a person's religious or spiritual beliefs are prior to the experience. It works for people with deep religious convictions and atheists as well. In fact, it appears to work for anyone who is willing and able to participate in the procedure, and individual factors beyond that seem to be of no consequence. Also, interested colleagues have been able to achieve nearly identical results after being provided some instruction. In short, the technique appears to be very robust and the outcomes do not appear to be restricted by any identifiable patient or therapist variables.

The most difficult part of losing a friend, comrade, or loved one is the deep and painful feeling of loss or disconnection. The goal of current grief therapies is to help survivors achieve a level of acceptance of the loss that allows them to move on and learn to enjoy life, in spite of some continuing pain. The prevailing belief among grief therapists is that grief is never fully resolved. The approach to treating grief, which is provided here, is radically different. The goal with ADC inductions is psychological reconnection and resolution.

In the simplest, but not necessarily least profound of these induced ADC experiences, the individual "sees" the deceased as happy and at peace, and still very much alive, although in a different place. Usually some form of communication also occurs. As a result of the experience, the pain of disconnection vanishes, and is replaced by a loving reconnection. The experience dramatically erases any doubts about a belief in an afterlife. Just as people who have had a near-death experience 
(NDE) no longer believe death is final, people who experience an ADC no longer believe their friend or loved one is really gone. Griefwork from this perspective, therefore, is not a matter of saying good-bye, but hello.

\section{General Considerations in the Standard Treatment of Grief}

Grief is a very individual process that involves a variety of psychological reactions to the perception of loss. It is a natural and spontaneous response, and typically a wide variety of emotions are involved, most prominent of which are feelings of loss, guilt, and anger. Mourning involves the sharing of the feelings of grief with others, and therefore involves the social and cultural meaning of the loss. Bereavement is the objective state of having suffered a loss.

Post-traumatic stress disorder, or PTSD, develops from an exposure to an event that involved either actual or threatened death, physical injury, or violation of physical integrity. The three clusters of symptoms are the re-experiencing of the traumatic event, such as intrusive recollections, nightmares, and feelings of reliving the event through flashbacks; the persistent avoidance of reminders of the incident; and the persistent feelings of increased physiological arousal.

Grief and PTSD are similar in some very important ways. The core issue of both grief and PTSD is loss, although in either case, the loss does not necessarily involve a death. In situations of overwhelming threat in which no death occurred, for example, the core issue of PTSD is often the loss of a sense of invulnerability to harm. Grief can be associated with any loss, such as loss of a job or a marriage. In this paper, the loss always involves the death of another person; therefore, the induction procedure I describe is not appropriate for cases of grief and PTSD that do not involve a death. Since the core issues and dynamics of grief and PTSD are nearly identical when a death is involved, I make no further diagnostic distinctions between the two here. However, it should be made clear that PTSD is a complex disorder, and although $\mathrm{ADC}$ inductions provide resolution of feelings of loss, guilt, anger, and directly related intrusive symptoms, just as they do with grief, they have less of an impact on other symptoms, such as those associated with avoidance and physiological arousal. This is especially true of cases in which the PTSD is chronic and involve multiple traumas. Therefore, although ADC inductions address the most painful aspect of trauma when a death is involved, they are not appropriate for all traumas, and they do not directly address all of the PTSD symptoms, even when death is the primary issue. 
Grief is a very individual matter, and is influenced by such factors as the age of both the deceased and the survivor, the survivor's support system, the survivor's relationship to the deceased, and the cause of death. Moreover, grief usually never fully resolves. Most grief counselors would agree that it generally takes people from one to two years to reconcile a loss to the degree that they can again find enjoyment in a life without their loved one. It takes even longer than that in cases which involve the death of a child or a spouse after many years of marriage. Moreover, reminders of the loss can continue to trigger any unresolved aspects of grief for a lifetime. The primary emotional components of grief are generally recognized as the feelings of loss, guilt, and anger.

The bond between the living is love, but when a loved one dies, the bond is pain. Helping a client work through the pain and achieve acceptance is complicated by guilt and fears of complete disconnection with the deceased. Guilt can also be associated with a wide variety of issues, but most commonly for having "unfinished business" with the deceased. Examples of unfinished business include never having said "I love you," having unresolved interpersonal difficulties with the deceased, or feeling responsible in some way for the death of the deceased. Generally, those who grieve also feel intense anger, because someone very important has been taken away. Both guilt and anger can be related to issues of blame and responsibility.

The overall goal in standard grief therapy, therefore, is to help survivors achieve a level of acceptance of their loss that allows them to learn to enjoy life again, in spite of these ongoing difficulties. The approach provided here is radically different from this perspective. The psychotherapeutic procedure that I will describe below, instead of promoting acceptance of the perceived disconnection, actually provides complete psychological resolution through establishing an experiential reconnection with the deceased.

\section{Some Insights and Breakthroughs}

People who experience normal grief, and especially those who suffer a traumatic loss, generally experience a variety of intense emotions. Feelings frequently vacillate between anger, guilt, and deep sadness or loss. A person who grieves, for example, may be crying one moment, and full of anger or even rage the next. A large portion of the job of a psychotherapist is to provide a supportive psychological environment in which these feelings can be openly expressed. Patients are told that these feelings 
are completely normal and they are encouraged to express them. By working through or processing these feelings, patients are usually able eventually to achieve some level of acceptance of their loss and an improved capacity to get on with their lives. Generally, however, the loss is never fully resolved, and stimuli or reminders of the loss can trigger periods of sadness, guilt, or anger for a lifetime. Over time these episodes usually decrease somewhat in both frequency and intensity.

I have learned some important lessons over the years while treating people who suffer from loss. One insight is that feelings generally come in layers, or in a predictable order, both in terms of psychological importance and a patient's readiness to address them. Attributions of blame and responsibility, which are related to feelings of guilt and anger, can be very important from a legal point of view, but psychologically, these issues are peripheral to the core and more painful feelings of loss. Some level of acceptance can be achieved only when the feelings of loss are worked through to some degree. In psychotherapy, therefore, the expression of feelings of guilt and anger should be encouraged, so they can be processed or worked through, which in turn allows the issue of loss to be directly addressed.

This was the general state of the art of griefwork, with some of my own clinical insights included, when a major breakthrough in psychological treatment was discovered in the late 1980 s by Francine Shapiro, who, while walking through a park one day and feeling upset about some troubling and recurring thoughts, found herself spontaneously shifting her eyes back and forth. She noticed that the shifting of her eyes greatly reduced the negative emotional charge and intrusive nature of her thoughts. She then tried the technique on friends and colleagues, and surprisingly, got the same results. She went on to conduct controlled scientific studies on subjects diagnosed with PTSD, and found that the technique produced psychotherapeutic outcomes unprecedented in the field of mental health.

My colleagues and I, who had been treating patients with PTSD for many years, were initially very skeptical about what appeared to be a very simplistic procedure that produced such unbelievable psychotherapeutic results. We were open-minded enough, however, to at least give it a try. I will never forget our first application of the new procedure. One of our PTSD patients, who had been in ongoing psychotherapy with us for over three years, gave us informed consent to attempt the new and experimental procedure. With myself and another psychologist observing, our colleague accomplished in 30 minutes what the patient had been unable to do in three years. It was as if somebody had just turned 
on a lightbulb for the first time. For the next few years, psychologists across the country, myself included, began to publish scientific studies in mainstream psychological journals which supported Shapiro's findings (Lipke and Botkin, 1992). The technique is now known as eyemovement desensitization and reprocessing, or EMDR.

The EMDR technique involves getting the patient to move his or her eyes in a particular rhythmic fashion while at the same time attending to a particular aspect of the traumatic memory. The therapeutic results, to those familiar with the treatment of PTSD and grief, are nothing less than astonishing. For many patients, significant desensitization of the intrusive images and feelings associated with a particular loss can occur within a single session. Similarly, EMDR also results in a rapid cognitive restructuring of the traumatic event. We are thus in many instances able to achieve in one session of EMDR what we had been unable to accomplish after years of traditional psychotherapy.

How EMDR works is still a matter of some debate. However, most psychologists familiar with the procedure would agree that it somehow greatly increases the brain's ability to process information. Shapiro's "Accelerated Information Processing" model is consistent with clinical observations. It has been known for some time that the shifting of the eyes is associated with increased brain processing. The most familiar example is that of rapid eye movement (REM) sleep, which occurs when we dream. It is generally agreed that the increased processing that occurs during dreaming causes the eyes to shift back and forth. With EMDR it appears that the reverse is also true, that a purposeful shifting of the eyes causes an increase in the brain's ability to process information.

Since one can literally accomplish in a single session with EMDR what used to take years with more traditional therapies, some rather amazing events began to occur in my psychotherapy sessions. I found, for example, that EMDR allowed such a rapid processing through the layers of anger and guilt, that patients were frequently ready to access their feelings of loss in the first session. But even more than that, I found that if the patient could access the feeling of loss, to any degree and at any time, in spite of concurrent feelings of anger and guilt, and focus on it with EMDR, a clinically significant level of acceptance was imminent. When the feeling of loss is rapidly processed in this manner with EMDR, one will also usually find that all of the associated anger and guilt have vanished, without even being directly addressed. This clinical observation supports the hypothesis that anger and guilt serve a protective or defensive function against the more painful feelings of loss. When the loss is directly and successfully processed, and some level 
of acceptance is achieved, there is simply little reason for the patient to continue to feel anger or guilt.

With these thoughts in mind, I began to use EMDR in an even more focused way on the core issue of loss. When I did, something else very unusual began to occur. Some of my patients reported that during EMDR they made what they believed to be a spiritual connection to the deceased person they were grieving. But even more than that, they also claimed that they "saw" and "talked to" their deceased friend or loved one! Remarkably, whenever this occurred, not only did the patients immediately achieve a significant level of acceptance of the loss, they in nearly all cases also experienced a complete resolution of the loss, and all related symptoms, such as anger, guilt, and intrusive images. Many patients literally began the session in despair, and left feeling joyous. At first I believed that the EMDR had produced some sort of hallucinatory event, and that the results would not last. However, my attempts to obtain follow-up data indicated that the results did indeed last, and in fact, the results appeared to hold up over time in every case. Other clinicians have reported the production of similar spontaneous ADCs during standard EMDR treatment, with similar therapeutic results (Parnell, 1996).

After these experiences occurred a number of times in a more or less unexpected fashion, I wanted to understand why it was that some of my patients had this experience, while others did not. I went back and examined each case in which the experience occurred, and each case in which it did not. I was then able to discern a particular sequence of psychotherapeutic events that led to the experience. When I then applied these principles with other patients, I found that it appeared that I could induce the experience in all of them. The most remarkable aspect of this whole endeavor was that I found that it was actually very easy to do.

\section{ADC Induction Procedure}

It is important to emphasize to the reader that one must already be trained in EMDR in order to be able to use the ADC induction technique described here. For mental health professionals to obtain a "certificate of completion," they must successfully complete Shapiro's level I and level II workshops. All mental health professionals recognized by state or federal licensing authorities as independent providers of mental heath services are eligible for EMDR training.

Shapiro has created some controversy in the field by maintaining strict control over the teaching of EMDR. Mental health professionals can learn the technique only by attending her two officially sanctioned 
workshops, which are now provided on a regular basis throughout the United States and in a few other countries. She has proceeded in this manner because EMDR is so powerful that misuse and harm to patients is a real possibility. I received both level I and level II training several years ago, and have served as a facilitator at her workshops.

Clearly, all clients or patients considered for an ADC induction should be thoroughly screened. Although I never had a patient who got worse as a result of an $\mathrm{ADC}$ induction, the possibility certainly exists. Theoretically, an ADC could trigger a psychotic reaction in those with a history of severe mental disorders. The most important consideration in screening patients is the potential adverse reaction to EMDR. Psychological decompensation could occur in those with a history of severe abuse. As any adequately trained EMDR therapist is aware, there exists the possibility of inadvertently uncovering repressed or partially repressed traumatic material. A good history is therefore essential. Current factors I routinely assess are overall psychological health, concurrent stressors, medications, substance abuse, suicide potential, and available social and professional support systems.

A good psychotherapeutic relationship is essential, as are warmth, empathy, and genuineness on the part of the therapist. It simply will not work if the patient does not trust the therapist and withholds valuable information. Prior to the induction, it is important that the patient talk about his or her relationship to the deceased and the circumstances of the death. This not only assists the patient in achieving an appropriate focus, it also alerts the therapist to the potential issues that might arise during the induction. The therapist also needs to be aware of how the $\mathrm{ADC}$ is unfolding, so that the experience can be properly guided.

When inducing ADCs, it is important to keep the principles described in the prior section in mind. It is also my belief, that in any application of EMDR, that the psychotherapeutic process proceeds much more efficiently if the most distressing issue is addressed first. If the memory with the greatest emotional charge is not addressed first, it can unexpectedly intrude into consciousness while one is attempting to deal with a memory that is less emotionally charged. When this occurs, no further progress can be achieved unless the more distressing memory is addressed with EMDR. If the patient is unwilling to address the more distressing memory, then all progress is halted, and the patient frequently feels worse as a result of uncovering two memories, for which further working through is no longer possible. I therefore routinely have patients rank order their issues prior to the application of EMDR. I have found that this allows psychotherapy to proceed more efficiently, more rapidly, and with fewer complications. 
Inducing ADCs works better when there is a cooperative effort between therapist and patient. Some of my colleagues, when they first attempted to induce ADCs and were unsure of the technique and their own skills, introduced the procedure to their patient in a subtle fashion. Risk of failure was therefore avoided because the patient was not quite sure what the therapist was trying to do. With this approach ADCs did occur, but the results were variable. I begin, therefore, in setting up a cooperative endeavor by explaining the procedure and inquiring about the patient's religious or spiritual beliefs.

For patients who do not believe in an afterlife, I ask them simply whether they believe that an afterlife is even possible. Since almost all patients will admit that there is no way to know for sure, the procedure is then offered as a cooperative experiment. The expectation that the procedure may not work appears to have no effect on the production of the experience. The patient needs only to be willing to give it a try. If the patient professes a belief in an afterlife, a different route is taken. Although these patients might initially see some potential value in the procedure, it is essential that they be instructed not to project their own beliefs into the experience. Sometimes patients need to be reminded of this more than once during the course of the ADC induction. Since ADCs appear to be universal experiences, and unrelated to a patient's particular beliefs, any attempts by the patient to create an experience consistent with his or her religious beliefs will prevent an ADC from occurring. Some patients, for example, expect to see the deceased burning in hell or floating around in the clouds in a spiritual body. In such cases, the production of an ADC is blocked and essentially nothing happens. Therefore, whether the patient has religious beliefs or not, the critical factor in ADC inductions is that the patient is open to the experience, and in a receptive mode. I sometimes tell my patients to let the deceased do the work of finding them, and that their only job is to "open the door" to let them in.

Prior to the first set of EMDR, patients are instructed that they are to think about where their deceased friend or loved one is right now, while at the same time receiving the first set of EMDR. I use the phrase "right now" in order to discourage the patient from attempting to bring up a memory of the deceased, which is a rather common tendency. At the same time, I encourage the patient not to attempt to create the experience but just to be open to whatever happens. My co-therapist presents the technique in a more neutral manner by simply instructing the patient to "hold the thought" of the deceased person while receiving EMDR. The advantage of this approach is that it decreases patients' attempts to project an expectation of "where" the deceased is "right 
now." However, this approach also increases the likelihood of the patient bringing up a memory of the deceased. Both approaches seem to work equally well, and these minor differences therefore appear to be of no consequence. My co-therapist's technique provides a better argument that the patient's experience is not influenced by the therapist's suggestion. However, I continue to use my approach for reasons of clinical expediency. In either case, whether the patient attempts to construct the experience, or bring up a memory, it is almost always sufficient simply to remind the patient to put his or her expectations on hold, and just go with the experience.

Patients are also instructed beforehand to close their eyes for a period of time following each set of EMDR in order to allow the experience to unfold. They are also told, however, that if a negative intrusion occurs, such as a bloody scene or an image of the deceased in a casket, they are to open their eyes and inform the therapist. Besides expectations and projected beliefs, negative intrusions can also block the ADC experience. Intrusions can take many forms besides distressing images, such as negative feelings or thoughts, or uncomfortable physical sensations. If intrusions occur, the therapist simply applies EMDR to whatever is intruding, and an ADC induction is attempted again. Intrusions do not have to be desensitized completely, but only enough to allow the ADC to develop, because once an ADC is achieved, all associated negative symptoms generally disappear. It is important to point out that if the patient's loss is traumatic and severe intrusive symptoms are part of the overall clinical picture, it is better to desensitize these intrusive symptoms to some degree before attempting the induction. If the intrusions are mild to moderate, the therapist can go ahead and attempt an $\mathrm{ADC}$ induction, and provide EMDR on any intrusions that arise during the course of induction.

Frequently, not all issues associated with the loss are resolved with a single ADC induction. For this reason, it is essential to evaluate the patient after each experience. If an issue is left unresolved, simply instruct the patient to bring that issue ("to have it in mind") and induce another ADC. It is important, however, that the patient maintain a receptive mode and not attempt to recreate the image he or she had in the preceding ADC.

Patients are generally surprised, and even somewhat shocked, by their ADC experience. In my experience this has never been a very serious issue and most people readily change their beliefs to assimilate their experience. In fact, nearly all patients seem to like their new way of thinking more than the old. Nevertheless, some time should be taken to 
evaluate this aspect, and to assist patients in framing their experience in any way that is comfortable for them.

\section{Additional Clinical Observations}

Although the following are not frequently observed during ADC inductions, they occur with enough regularity to merit some attention. First, although going through a tunnel or passageway and towards light is one of the universal elements of the experience, it is at times associated with the patient not being fully relaxed, usually because the patient is trying too hard. If the patient experiences some frustration getting through the tunnel, inquire whether the patient is indeed feeling this way, provide a set of EMDR to promote relaxation, and then induce the ADC again. Frequently, the patient will then immediately experience the deceased. In general, any time the patient appears to be trying too hard and is unable to achieve an $\mathrm{ADC}$, it is helpful to use a paradoxical approach by instructing the patient not to attempt an ADC during a set of eye movements, but just to focus on relaxation. An $\mathrm{ADC}$ frequently then develops because the patient gives up his or her attempts to create the experience, which then allows the $\mathrm{ADC}$ to occur naturally.

Second, the ADC experience typically lasts only as long as it needs to from a psychological point of view. When all issues have been resolved, sometimes patients want to linger in the experience, but these patients frequently report that the experience rapidly fades. It can be supportive to point out to these patients that this is a common experience. Usually this is only a minor issue because of the overwhelmingly positive nature of the experience that has just ensued.

Third, a few patients have expressed a concern prior to the experience that the deceased, for whatever reason, will be seen in hell. Again, simply instruct the patient to withhold all expectations about the experience. No one has yet reported a hellish scene. It is also interesting to note that even when the deceased did clearly live a life of low moral character, which has even included murder, they are nevertheless experienced as peaceful and happy, as having learned from their mistakes, and as having taken responsibility for their actions. They are also experienced as concerned about whatever pain or suffering they caused other people in life. The issue of unfinished business, then, is experienced by survivors as important to the deceased as well.

Fourth, when I first began doing ADC inductions, I was somewhat surprised that a successful ADC induction with the death of one person 
did not seem to generalize to other deaths. Even though ADC experiencers, in almost all cases, are subsequently convinced of the reality of an afterlife, a successful resolution appears to have little or no effect on the grief associated with other losses. This observation suggests that it is the experience itself, and not any subsequent changes in beliefs, that is responsible for psychological resolution. This hypothesis is further supported by the finding that even those who do not believe in the spiritual authenticity of their experience, nevertheless report full resolution of grief.

\section{Data Summary}

Out of 84 patients for whom an ADC induction was offered, 83 (99\%) were willing to participate in an induction. Of the 83 patients who participated in an ADC induction, $81(98 \%)$ achieved an ADC, defined as any perceived sensory contact with the deceased. Of the 81 patients who achieved an ADC, $78(96 \%)$ reported full resolution of grief following the $\mathrm{ADC}$, and $76(94 \%)$ believed their ADC was an actual spiritual contact. Of those 76 patients who believed their ADC was an actual spiritual contact, only $6(8 \%)$ had believed prior to the ADC that actual contact was possible.

This summary is based upon the first 84 patients to whom I offered an ADC induction. Although an overwhelming majority of patients who achieved an $\mathrm{ADC}$ chose to do additional ADCs with other deceased individuals, only first attempts are represented here. The total number of all $A D C$ inductions I was involved in, including a few conducted by my co-therapist, whom I supervised, exceeds 400 . In general, $A D C s$ become even easier to induce with practice. It is clear from these numbers that patients or clients are very willing to attempt an induction for the first time, even though they generally believe beforehand that such an experience is not possible. This, of course, depends upon the trust your patient has in your ability as a therapist and his or her willingness to try something different, something that might even sound a little "crazy" at first. If your patient is then willing and able to participate in the procedure, an ADC will usually occur. It is also clear that people who experience induced ADCs, in almost all cases, believe that their experience was actual contact with the deceased. The foregoing was the only information I recorded on a regular basis, other than the verbal reports of my patients. Although I initially had some interest in the potential effects of varying prior belief systems on ADC induction outcomes, I did not keep a record of those data. However, I have worked 
with many patients who described themselves as atheists, many who were unsure about their beliefs, and many who professed strong religious convictions. The fact that 98 percent of patients achieve ADCs no matter what they believe, as long as they are able and willing to participate in the procedure, strongly suggests that the difference in subjects' prior beliefs systems is of little consequence.

\section{Cases}

I provide here brief summaries of a few actual psychotherapy sessions in which ADCs were induced. In none of these cases did the patient come to psychotherapy seeking an ADC, and therefore, the ADC procedure was introduced during the course of psychotherapy. Identifying information in all cases has been altered to maintain confidentiality. Although some of these patients sought psychotherapy for help in dealing with the loss of a friend or family member, for others, the issue of loss was identified somewhat later in therapy as a contributing factor to their primary problem. For most patients, after they had successfully experienced an initial $\mathrm{ADC}$, they became interested in contacting other deceased family or friends. In these cases, the loss frequently had nothing to do with the primary problem.

The cases presented here were chosen for inclusion primarily because they exemplify a particular aspect of ADC experiences that has occurred with some regularity. These particular cases were further selected for inclusion in this article because they illustrate the similarities between ADCs induced by EMDR and NDEs; it should understood that many ADCs induced by EMDR do not include these NDE-like features. My goal in all of these cases was to help people with real and sometimes very difficult problems. This was not a research project, and therefore a standard set of questions was not asked in every case, other than the ones listed in the Data Summary above.

\section{$B o b$}

Bob and his unit had set up camp for the night in Vietnam. He and two buddies had guard duty and they were ordered to shoot anything that moved outside of their perimeter. Later that night, they detected movement in the bush not too far from their position. All three opened fire, and it appeared that they hit whoever or whatever it was. They had to wait for daylight, however, to go out and see what it was. The next morning they all went out and found that they had shot and killed 
a Vietnamese woman and her infant child. The woman was unarmed and for some unknown reason had wandered close to their camp. At the time, Bob was enraged at the senselessness of what had happened. For many years since the incident Bob has suffered from intrusive images of their dead bodies. When he presented this memory in psychotherapy, his primary feeling was overwhelming sadness.

The usual induction procedure was provided. However, in Bob's ADC he spontaneously went back in time to the moment the woman and child died. Although during the incident he did not see the bodies until the next morning, in his ADC he saw what looked like the spirits of the mother and child rise out of their bodies at the moment of death. The mother then held the child in her arms, turned, and proceeded to drift through a large tunnel and towards a bright light. They had a very peaceful look on their faces and they appeared to move with a sense of purpose. Bob's feeling of sadness was replaced by a feeling of happiness, which he experienced during his ADC. He was also comforted by his knowledge that the mother and child had maintained their loving relationship. He believed that his experience proved that there is life after death. Bob was somewhat confused, however, by the appearance of the bright light in his ADC, because at the time of the incident it was completely dark. Bob was unaware of NDE reports, which I offered as one of the possible interpretations. A month later, after Bob successfully completed work on some other issues, he terminated psychotherapy. At that time, he no longer felt sad about this incident and all associated intrusive images had disappeared.

Experiencing the NDEs of others during an $\mathrm{ADC}$ is not rare, and occurs most frequently when there was no relationship between the deceased and the ADC experiencer. It is also noteworthy that Bob knew nothing about NDEs prior to his ADC experience.

\section{Nancy}

Nancy's pregnancy was uneventful until the ninth month. She began vomiting and could no longer feel her baby's movement. An ultrasound revealed no fetal heart beat. Labor was therefore induced, but Nancy went into a hypertensive crisis and her baby was delivered dead. Nancy was near death herself for the next three days. At some time during those three days, Nancy experienced an NDE in which she saw her baby and her mother, who had died a few years earlier, standing together, holding hands, and looking very happy. Her baby was looking up at his grandmother. Her mother then said to her, "It's 
okay." Behind them was "a bright comforting light." Nancy was somewhat surprised that her baby was standing, even though he looked like a newborn. Because Nancy was so critically ill herself, her NDE provided some comfort to her only after her own physical condition had improved. These events happened six years prior to our meeting. In spite of her NDE, she continued to experience some grief over the death of her baby, especially at the time of the year that the loss occurred.

Nancy was enthusiastic about the ADC procedure because her NDE had convinced her that such experiences were possible. During Nancy's $\mathrm{ADC}$, she again saw her son with her mother, and they both looked happy and peaceful. There were some differences, however, between her NDE and her ADC experience. This time her son looked older and much healthier than he did before, and instead of looking at his grandmother, he was looking at Nancy and reaching out with both hands towards her. Overall, Nancy had the sense in her ADC that they were moving toward her, and not away, which she felt during her NDE. There was also no bright light behind them as there was in her NDE. After her ADC, Nancy explained that her ADC was "much clearer and more focused" than her NDE, although that may have been due to her being heavily medicated at the time of her NDE. She experienced her ADC as more comforting though, because of her sense that her mother and son were moving towards her and not away. At the end of the session, Nancy reported a much stronger connection with both her son and mother, and she believed her grief had fully resolved. A follow-up visit seven months later supported her belief. I also further questioned Nancy about her evaluation of her two experiences. She was convinced that her ADC was not merely an activation of the memory of her NDE. She was sure that they were two separate experiences that both tapped into the same spiritual reality.

This case provides an example of how people who have had both an induced $\mathrm{ADC}$ and an NDE subjectively experience the two as the same phenomenon. People who have had an NDE and an induced ADC where the same deceased person is not involved in both experiences are similarly convinced.

\section{Pam}

Pam's mother died nearly 30 years ago when Pam was 14 years old. She and her mother, as the only females in the family, developed a close relationship. Her mother lived only three months after being 
diagnosed with breast cancer. Her father and three brothers grieved her death, but Pam believed it was her job to take her mother's place as the strong one in the family, and as a result, never fully addressed her own issues regarding her mother's death. A brother also blamed Pam for their mother's rapid demise because the mother remained active in Pam's life until her death. Pam has been and continues to be a successful physician; however, she maintains an extremely demanding professional schedule that brings her, at times, to the point of exhaustion. After a year and a half of psychotherapy with another therapist, she had made some progress in terms of allowing herself to express her grief, and she had come to realize that her overly responsible caretaking role was tied in many ways to her response to her mother's death. However, these improvements had done little to help her make any significant changes in her routine, and she continued to experience significant guilt and loss over her mother's death.

In the first $\mathrm{ADC}$ attempt Pam found herself going through a tunnel and towards a bright light, but she found herself getting frustrated because she could not get to the end of the tunnel. She was unaware of the significance of the tunnel and light, and therefore it was reassuring for her to hear that it meant that the experience was beginning to unfold. After some EMDR to promote relaxation, another induction was performed. This time her mother was there. During her relatively long ADC, a few tears rolled down Pam's face while she kept her eyes closed. When it was over, she opened her eyes and was very excited about what had happened. She stated, "I saw my mother very clearly... She looked younger and thinner.... My mother had put on weight the last ten years of her life.... She looked healthy, happy, peaceful, and she had a spark in her eyes that seemed to emanate a glow around her." Pam then laughed and said, "My mother was sitting on a large rock by the beach in one of those old-style bathing suits, but the surroundings were more beautiful than any beach scene I've ever seen." Pam's mother communicated to her that she was very proud of what she had accomplished in her life, and that there was no reason for her to feel guilty about anything. Pam experienced "a warm connectedness that we used to have." Pam also pointed out than when her mother was alive "there was always a touch of sadness in her smile, but that was gone and she appeared to be genuinely happy." Pam then stated, "I can't believe how peaceful I feel, like there's been a tremendous burden lifted off of me ... and I have the sense that she is not gone and will always be with me." Pam felt that all her issues related to the death of her mother had completely resolved. She emphasized more than once how unexpected her experience was. 
Ten months later she reported that she continued to feel much better, and that she could still experience that same peaceful feeling when she took the time to think about it. Although she had made plans to cut back on her rigorous schedule, it was too soon to evaluate her success in that area.

\section{Gary}

When Gary was a medic in Vietnam, he had an ongoing difficult relationship with his commanding officer. At one point, someone had stolen Gary's rifle, and his officer, not believing his story, ordered Gary to go out on the next mission unarmed, even though other weapons were available. Although Gary survived the mission, he felt anger and rage towards the officer for putting his life in jeopardy. His anger never subsided. Gary believed for the last 30 years that if ever saw the officer again, he would kill him.

Although Gary had experienced an ADC in a prior session, for this issue, standard EMDR was provided in order to decrease his fear associated with that mission, which he continued to reexperience, and to decrease his anger towards the officer. After the fear was desensitized significantly, the anger was addressed. During the next set of EMDR, Gary spontaneously saw the officer standing in front of him with a concerned and caring look on his face. He told Gary that he was very sorry for what he had done, and for all the problems that Gary's ongoing anger has caused him in his life. The officer appeared to Gary to be very sincere. Gary's anger completely resolved, and he said that he forgave the officer. Since Gary had previously experienced an ADC and believed that it was actual spiritual contact, he was very surprised that person still living would appear in an ADC. After his ADC, he went to the book that lists the names of everyone who died in Vietnam. He discovered that his officer's name was in the book, and that he was killed soon after Gary left Vietnam.

It is significant that each time someone who was thought to be alive appeared in an $\mathrm{ADC}$, we were later able to verify that the person had in fact died. It appears that only the deceased are experienced in ADCs.

\section{Mark}

Mark was involved in a very serious car accident nearly 25 years prior to our session. Although Mark was uninjured, two adults and a 12-year-old girl, who were in the other car, were killed. He reported that 
he knew nothing else about the victims because he was taken away in a different ambulance, and he subsequently avoided all television and newspaper reports of the incident. The accident had been Mark's fault and he was found guilty of negligent homicide. This incident completely changed Mark's life. Although he had been a good student and had plans for a professional career, his deep sadness and severe guilt resulted in a dysfunctional life, which included recurring major depressions, two suicide attempts, failed marriages, drug abuse, and employment difficulties. Mark believed that since there was no way to undo what had happened, he was destined to suffer for the rest of his life.

After some preliminary EMDR to alleviate anxiety, an ADC was induced. Mark saw all three of the victims "standing together and smiling with a look of joy, peace, and contentment." They seemed "very happy being together and liked very much were they were." Although he had never seen these people before, he was sure it was they. He could see each one very clearly, and especially the girl, who was standing in front of the two adults. She had short red hair, freckles, and a distinctive smile. Mark also somehow got the clear impression that the male adult, who began to walk around in the scene, was communicating to him that he had multiple sclerosis before he died, and that he was happy about the fact that he was now able to move around freely. Mark privately told all three that he was very sorry about what had happened and that he felt very sad about the whole thing. Mark reported that they gave him the message that they had been waiting to hear what he had to say, and that they then forgave him.

Mark was astonished by his experience. He said, "I didn't picture all of this; it came to me, as clear as I'm looking at you right now... I didn't imagine it; I couldn't have imagined it." His feelings of sadness and guilt appeared to have fully resolved. He felt as though "a huge burden has been lifted off of me." He had some concern that I would think he was "crazy," but I reassured him that was not the case. Mark left the session "feeling great." The next day, however, I received a frantic phone call from Mark. He had to see me right away. He was in my office within an hour. He explained that since he was feeling so much better, he stopped by his sister's house the night before, and asked her to get out the old newspaper clippings on the accident, which he knew she had kept in her attic. He "nearly freaked out" when he saw a picture of the girl with short red hair, freckles, and the same distinctive smile. The newspaper articles also reported that the man had severe multiple sclerosis and had been wheelchair-bound for a number of years prior to his death. 
Although the day before Mark believed that his experience was real, the newspaper clippings "proved beyond any doubt that it was real." His primary concern was that the spirits of these three people might change their minds and come back to punish him in the future. I was able to reassure him that, although I had considerable experience in inducing ADCs and had read hundreds of first hand accounts, I had never heard of a single case in which an ADC was either punitive or negative. I also explained to him that it was clear the day before that all issues between the three people and him had been resolved. He left my office feeling reassured and better again. Mark continued in therapy for about two months, during which time he addressed a different issue. During that time, all issues pertaining to the accident remained resolved, and he denied any further concern about a possible negative ADC in the future.

Only infrequently is it possible to obtain independent evidence which has some bearing on the validity of ADC content. For that reason, when it does occur, it is of interest. Of course, in this case, we must rely on the reliability of Mark's reports. Although the newspaper clippings "proved" to Mark that his experience was real, they do not constitute proof for the rest of us. Even if he had shown me the newspaper articles, one could argue either that Mark was lying about having not seen them, or that he repressed the fact that he had seen them because it was psychologically too painful for him to remember. Yet, I do not believe Mark was lying, and repressing that material appears very unlikely given his age at the time of the accident and his psychological history.

This case also illustrates a frequent observation that some deceased people appear to have not aged, even though they died at a relatively young age. After 25 years, the 12-year-old girl still looked like a 12-yearold. It is also noteworthy that Mark reported that the three victims of the accident were waiting to hear what Mark had to say. Although the victims were ultimately experienced as forgiving, it appears here that the resolution of unfinished business needed to occur first.

\section{Comparison of NDEs and Induced ADCs}

It has been 30 years since Elisabeth Kübler-Ross wrote On Death and Dying (1969), and a quarter century since Moody wrote Life After Life (1975). These two individuals, more than anyone else, sparked the public's interest in the experiences of those who come close to death. 
It is now commonly accepted that roughly one-third of all people who come close to death, upon regaining consciousness, report having had a wonderful and life-changing spiritual experience. Moody labeled these experiences "near-death experiences," or NDEs. He pointed out that as a result of medical advances in resuscitation techniques, many more people were being brought back from the brink of death than in the past.

The many books on NDEs that followed Moody's Life After Life generally support his observations regarding the content of the experience. The general sequence of events that occur when a person is at a point close to death includes floating out of one's physical body, a feeling of indescribable peace and happiness, going through a tunnel or passageway towards a light, meeting with friends and relatives who have previously died, seeing beautiful landscapes with bright and rich colors, experiencing a life review, meeting a loving being of light, and returning to one's physical body. It should be noted that the sequence is not invariant, and frequently only one or a few of the elements are reported.

The more I became aware of the content of my patients' ADC experiences, the more I realized that they were consistently reporting almost all of same elements of NDEs, but from a very different perspective. Whereas NDEs occur as one approaches death, in ADCs one experiences another who has already died. Aside from this obvious difference, the two experiences are essentially identical.

During ADCs the experiencer sometimes sees the whole body of the deceased, and sometimes only the face. In either case, they often appear radiant or surrounded by light. Children who die very young are usually seen as older, unlike the 12-year-old girl in Mark's ADC. People who were very old or ill prior to death are always experienced as younger and healthy. A face that was "worry-worn" in life will always appear peaceful and serene. Since the deceased are usually not experienced as in their more familiar physical form, therefore, they can be considered to be out-of-body, or perceived as not attached to the same physical body they left behind.

I have not had a single ADC case where the deceased did not look peaceful, serene, content, or happy. Almost all those who have had NDEs described a similar feeling of peace. The feeling is so pleasant that some NDE experiencers have difficulty expressing it in words. For the ADC experiencer, perceiving the deceased in such a profoundly positive emotional state greatly expedites the resolution of grief. In many instances, the person who has the ADC experiences the same feeling, as though it was somehow transmitted from the deceased. When 
this occurs, the feeling of peace, in most instances, immediately and completely replaces whatever feelings of loss or pain that the person brought to the experience.

ADC experiencers sometimes go through a tunnel or passageway before they get to the deceased. There is usually a bright light at the end of the tunnel, and experiencers somehow know during the experience that the deceased is somewhere in the light. People who have NDEs sometimes report the identical experience, and they too report meeting deceased loved ones in the light.

Meeting the deceased in both ADCs and NDEs is essentially identical. They are always loving encounters. The only difference is that, in NDEs, the conversation often involves the issue of whether the NDE experiencer is to remain there or go back to his or her body, whereas in $\mathrm{ADCs}$, the focus is almost always related to the grief, issues, or concerns of the experiencer, and is sometimes perceived as related to the issues and concerns of the deceased as well.

Beautiful landscapes are common in the reports of both NDEs and ADCs. Beautiful trees, hills, bushes, grass, and streams are frequently reported. Colors are typically brighter and richer, and sometimes even radiant in appearance. As one ADC patient said, "It was the greenest green I've ever seen." But even more than appearance, some NDE and ADC experiencers have reported the scenery itself exudes a feeling of peace and tranquillity, which is then transmitted to the experiencer.

Although survivors do not directly experience any portion of their own life review or that of the deceased in induced ADCs, the deceased consistently appear as if they have been through a life review. In the life review portion of NDEs, the person near death experiences his or her whole life in a few brief moments. The content of the experience generally includes a special focus on feelings that were experienced at different moments in life. However, the person near death not only experiences his or her own feelings, but also those of the other people in the experiencer's life at different moments. Thus, an important part of the life review appears to be the experience of the feelings that one caused in others, some of which are positive, and some negative. Those who have experienced life reviews report that it is a profound and life changing learning experience. People who experience life reviews generally develop an increased sense of empathy and an interest in serving others. In induced ADCs, the deceased are consistently experienced as having learned from their mistakes, and as having taken responsibility for how they treated other people in life. They also appear to be very concerned about any negative feelings that they caused in others during 
life. This is particularly evident in those cases in which the deceased lived troubled or even violent lives. With the above considerations in mind, NDEs and induced ADCs are actually very consistent in terms of the life review.

None of my patients ever reported seeing a being of light, nor has there been any indirect evidence that the deceased had such an experience. In NDEs, this experience frequently occurs in conjunction with the life review, and the being of light usually assists people in the evaluation of their lives. The being of light, however, is consistently reported as loving and compassionate, and any negative judgments which occur during the life review are generated by experiencers themselves, when they realize the pain or hurt that they caused in others at different times during their lives.

The relationship between NDEs and ADCs is further supported by the observation that a number of my patients, usually those who did not know the deceased personally, actually witnessed the NDE of the deceased during their own ADC. This kind of experience has been associated primarily with battlefield and hospital deaths. In these ADC experiences, a perceived two-way direct communication between the patient and the deceased usually does not occur; however, important information is nevertheless received by the patient which, so far, has resolved whatever issues the patient brought to the experience. Typically, during this kind of $A D C$, the experiencer sees a translucent body or spirit rise from the physical body at the point of death, usually with a very peaceful or serene appearance, and sometimes then proceed through a tunnel and towards light. Grief is resolved for the patient as a result of experiencing the other person's peaceful continuation of life at the point of death. Interestingly, none of my patients who had this kind of experience had been aware beforehand of NDE content, and all were very surprised, and some even a little confused, by the experience. Bob, for example, was initially confused because he did not understand how the deceased could have moved towards a bright light, because the death had occurred at night in the jungle.

A final argument that NDEs and ADCs are essentially the same phenomenon experienced from different perspectives is that those patients who have had both NDEs and induced ADCs all reported that both the quality and the psychological impact of the two experiences were essentially the same. These patients also believed, with certainty, that the two experiences tapped into the same spiritual reality.

In short, the remarkable similarities and overlap between NDEs and ADCs would lead one to conclude that they are at least closely related 
phenomena, whatever the mechanism might be. Perhaps, however, as experiencers have argued, they are the same spiritual phenomenon experienced from different perspectives, the NDE being from the point of view of a person approaching death, and the ADC from the point of view of an alive person contacting one who is already dead. Both suggest something about what the experience of death may be like, and remarkably, reports of both experiences are strikingly similar. If it turns out that they are both a connection to the same spiritual reality, then NDEs are not just transitory experiences that occur before one dies, because the deceased are experienced as having continued in the same general mode during ADCs.

\section{References}

Devers, E. (1997). Goodbye again: Experiences with departed loved ones. Kansas City, MO: Andrews and McMeel.

Guggenheim, B., and Guggenheim, J. (1996). Hello from heaven! A new field of research confirms that life and love are eternal. New York, NY: Bantam.

Kennedy, A. (1997). Your loved one lives on within you. New York, NY: Berkley.

Kübler-Ross, E. (1969). On death and dying. New York, NY: Macmillan.

LaGrand, L. E. (1997). After-death communication: Final farewells. St. Paul, MN: Llewellyn.

Lipke, H. J., and Botkin, A. L. (1992). Case studies of eye movement desensitization and reprocessing (EMDR) with chronic post-traumatic stress disorder. Psychotherapy, 29, 591-595, 1992.

Moody, R. A. (1975). Life after life. Covington, GA: Mockingbird Books.

Moody, R.A. (1992). Family reunions: visionary encounters with the departed in a modernday psychomanteum. Journal of Near-Death Studies, 11, 83-121.

Moody, R. A., and Perry, P. (1993). Reunions: Visionary encounters with departed loved ones. New York, NY: Villard.

Parnell, L. (1996). Eye movement desensitization and reprocessing (EMDR) and spiritual unfolding. Journal of Transpersonal Psychology, 28, 129-153.

Shapiro, F. (1995). Eye movement desensitization and reprocessing: Principles, processes, and procedures. New York, NY: Guilford. 